\title{
Editorial
}

\section{Forzados a cambiar}

La interpelación es una facultad constitucional que permite a la asamblea legislativa supervisar y evaluar las actuaciones del poder ejecutivo. Por consiguiente, es un instrumento para contrarrestar el poder de este último y así contribuir al equilibrio de los poderes del Estado. Con todo, la interpelación es un recurso del cual se echa mano cuando el poder ejecutivo se cierra a discutir sus políticas. En ningún caso se reduce a confirmar o destituir al funcionario cuestionado, aunque incluye tal posibilidad, si a juicio de los diputados aquél es incompatible con el cargo o demuestra ser incompetente o inmoral.

En la interpelación al presidente del Banco Central de Reserva se intentó someter a examen legislativo su gestión como rector de la política monetaria y financiera del pais, contra cuya estabilidad atentan defraudaciones millonarias como las de Fomiexport, Crediclub, Finsepro e Insepro así como también otras irregularidades e ilegalidades no aclaradas aún. De esta manera, lo que debió haber sido un mero ejercicio democrático se convirtió en un acontecimiento con amplias repercuciones en la vida nacional por la amplitud de su perspectiva, las expectarivas creadas y las emociones encontradas.

Más allá del juicio político partidista que se pueda hacer de la interpelación, ésta, en sí misma, es un hecho positivo para el proceso de democratización y, en particular, para la consolidación de la instirucionalidad democrática de El Salvador. Las resistencias no fueron lo suficientemente fuertes como para impedir que el proceso avanzara, forzado por las necesidades internas del país y las presiones externas derivadas de la modernidad capitalista.

\section{Empujados por la modernidad capitalista}

La interpelación puso en evidencia la no separación entre lo público y lo privado y la facilidad con la que se pasa de un ámbito al otro en El Salva- 
dor. El presidente de la república y sus asesores, incluido el presidente del Banco Central de Reserva, tratan asuntos de interés público, en este caso concreto, el estado de las finanzas, como si fuera un negocio familiar, pasando por alto disposiciones legales importantes que norman esa gestión. Algunos capitalistas nacionales, quienes al mismo tiempo son dirigentes del partido de gobierno, el cual financian, tienen acceso libre al poder ejecutivo y deciden según una curiosa mezcla de criterios empresariales, políticos y personales. Esta confusión de criterios y roles allanó el camino para los fraudes millonarios que ahora se lamentan. Esa combinación de relaciones familiares, empresariales y políticas no permitió controlar unas operaciones financieras que debían haber sido fiscalizadas con extremado rigor.

Hasta cierto punto, esto no debiera extrañar, porque así se han administrado la economía y la política salvadoreñas prácticamente desde los orígenes de la república. Las cosas habían salido bastante bien, hasta ahora, a las poderosas clases dirigentes, pero desde la perspectiva de la modernización de El Salvador, la no separación entre lo público y lo privado es inaceptable. La modernización no es una cuestión sólo de leyes, sino que además implica un cambio radical de mentalidad muy dificil de obtener, porque cierra la puerta al tráfico de influencias, a la información privilegiada y a otras prácticas corruptas bastante comunes en nuestro medio. Prueba de esa dificultad es que el poder ejecutivo así como persigue algunas prácticas ilegales continúa tolerando otras.

La interpelación puso en evidencia la no separación entre lo público y lo privado y la facilidad con la que se pasa de un ámbito al otro en El Salvador.

Cada vez es más claro que la intolerancia de las prácticas de empresas como Crediclub, Finsepro e Insepro responde a intereses de grupos rivales, los cuales utilizan el poder estatal para sus propios fines. Estos son más valiosos que el desgaste que el poder ejecutivo y ARENA puedan experimentar a raíz de la quiebra de dichas empresas. Es así como las prácticas tradicionales siguen predominando, pese a las tendencias modernizadoras que intentan establecer una frontera clara entre lo público y lo privado. La dirección de la política económica todavía está más determinada por razones políticas que técnicas. La competencia promovida por la modernidad capitalista es un ideal lejano. De hecho, lo moderno tiende a reducirse al predominio casi indisputado del capital transnacional y, en este contexto, lo global se vuelve sinónimo de modernidad. Se supone demasiado rápido que El Salvador ya habría alcanzado un estadio superior en su trayectoria hacia la prosperidad y el bienestar. Los hechos recientes cuestionan esta limitada idea de modernidad. 


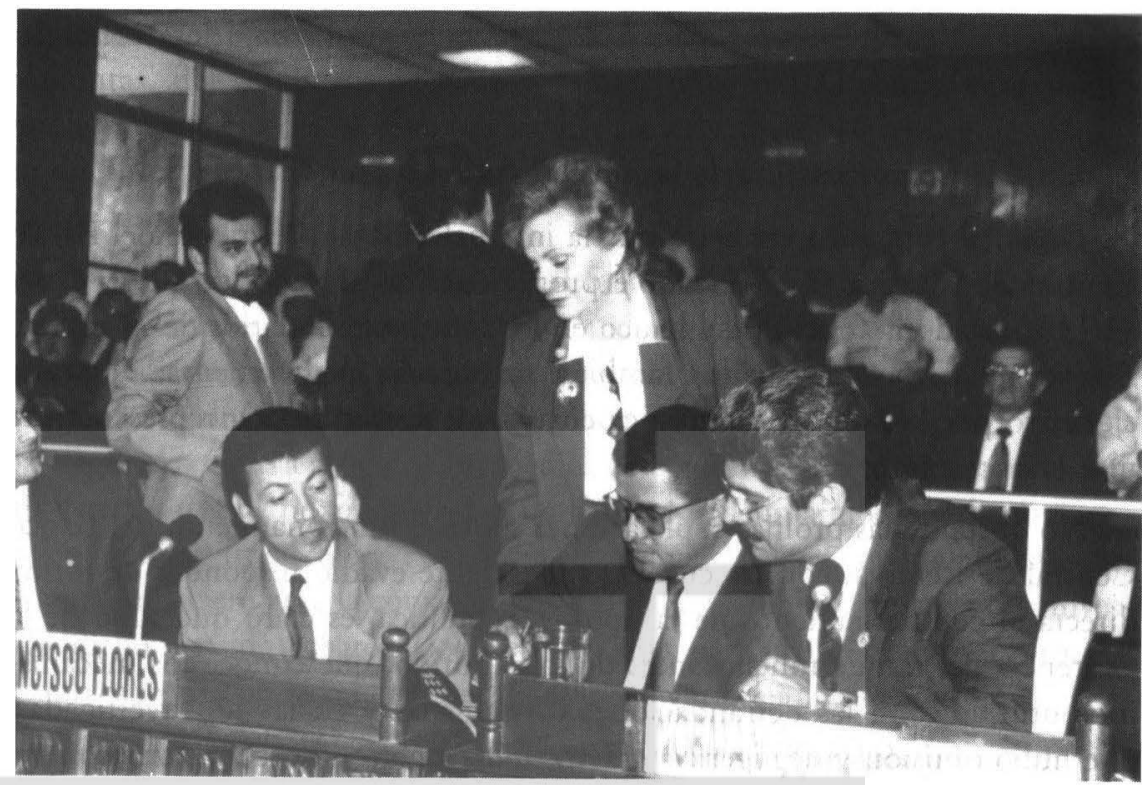

A pesar de esto, el proceso de transición de postguerra habría sido empujado en una dirección novedosa con la apertura de procesos judiciales contra varios connotados empresarios y dirigentes de ARENA, algunos de los cuales guardan prisión, la interpelación al presidente del Banco Central de Reserva, una investigación especial en el seno de la asamblea legislativa y la promesa de una revisión seria de la legislación financiera vigente.

Estas novedades son posibles, en primer lugar, por las realidades políticas traídas por dicha transición. En una asamblea legislativa controlada por ARENA, la investigación del sector financiero o la interpelación al presidente del Banco Central de Reserva o a cualquier alto funcionario del poder ejecutivo hubiera sido impensable. Por lo tanto, la oposición política tiene mucho mérito al haber sabido utilizar los espacios abiertos para interpelar -aunque después no haya sabido sacar todo el provecho que se podría haber esperado de este recurso constitucional.

En segundo lugar, la modernización neoliberal presiona con fuerza por imponerse y transformar las realidades nacionales existentes. Es así como el gobierno salvadoreño se ve confrontado con tendencias contradictorias, por un lado están sus prácticas tradicionales que responden a alianzas de carácter personal y privado, pero por el otro están las reglas de una competencia que quiere ser impersonal y pública y cuyo veredicto viene dado por las fuerzas del mercado. El ajustarse a esas reglas implica inexorablemente abandonar la práctica tradicional o romper con quienes se empeñen en continuar beneficiándose de ella. Esto no podrá hacerse sin pagar un costo político elevado, pero en ello se decide el futuro de la modernización que los bancos multilaterales exigen. El drama de la interpelación es parte de otro drama de dimensión nacional, protagonizado por 
el esfuerzo de El Salvador para colocarse a la altura del desarrollo del capitalismo mundial.

\section{2. ¿Un desafio por encima de las posibilidades?}

Desde el comienzo era claro que la interpelación al presidente del Banco Central de Reserva tenía un doble propósito. Por un lado, se quería saber cuál había sido la función del banco en los fraudes millonarios de Finsepro e Insepro; pero, por otro lado, también se buscaba pedir cuentas al poder ejecutivo por la política económica en uno de sus artífices y representantes más importantes.

No obstante las prolijas explicaciones sobre el funcionamiento del Banco Central de Reserva, con las cuales su presidente evadió responder de forma directa al cuestionamiento de la oposición política, es claro que supo de la existencia del fraude mucho antes de lo admitido, que conoce los mecanismos utilizados en las defraudaciones investigadas y en las no investigadas, que hubo omisión y negligencia grave e inexcusable al no garantizar con los recursos que la ley le otorga los depósitos del público, que su presidencia si no es incompatible al menos es cuestionable con la propiedad de acciones en los bancos privados más grandes del país y con la dirección de empresas que acuden a la banca para financiarse, que faltó a la verdad y ocultó información a la asamblea legislativa en forma deliberada.

A todo lo cual se agregó una acusación de otra índole, la cual responde al malestar predominante en muchos sectores por la dirección dada a la economía nacional. En efecto, al presidente del Banco Central de Reserva se le acusa también de incumplimiento de funciones en el ejercicio de su cargo por haber permitido que unos pocos bancos del sistema hayan podido concentrar una cantidad demasiado elevada de depósitos y utilidades, justificando esa concentración como simple resultado de las fuerzas del mercado. Desde una perspectiva formal, las respuestas del funcionario fueron impecables, pero no convincentes.

Poco después, el ex superintendente del sistema financiero señaló que el presidente Calderón y sus asesores más cercanos conocieron con anticipación del fraude, lo cual explicaría la actuación del presidente del Banco Central de Reserva en la asamblea legislativa, donde siguió un cuidado texto preparado por sus asesores. Al responder, no dijo más de lo estrictamente necesario. Su objetivo no era informar sobre los hechos, sino contener el daño que la verdad podía ocasionar en las altas esferas del poder. En este sentido, el interpelado se sacrifico, demostrando una lealtad pocas veces vista al poder ejecurivo, a ARENA y, por qué no decirlo también, a los banqueros. Los diputados, por su parte, no pudieron quebrar las defensas levantadas por el poder ejecutivo por falta de conocimiento sobre el funcionamiento de la economía nacional y por no preguntar de forma lúcida. El 
presidente del Banco Central de Reserva supo sacar partido de esta clase de preguntas, del modo de hacerlas y, sobre todo, de la ignorancia sobre el sistema financiero de los diputados y sus asesores. ARENA consiguió, explotando el respeto debido a cualquier persona, neutralizar el potencial revelador de la interpelación.

De todos modos, el resultado final fue contrario al partido de gobierno. El primer balance le fue favorable. El presidente del Banco Central de Reserva parecía haber superado la prueba con facilidad, es decir, no reveló información comprometedora. Su posición parecía sólida y su permanencia en el cargo estaba asegurada. Con la ayuda de los medios de comunicación social proyectó una imagen positiva de profesionalismo, honestidad y víctima inocente de una oposición política implacable. Pero las declaraciones del ex superintendente del sistema financiero ante la comisión especial de la asamblea legislativa que investiga dicho sistema echaron por tierra lo que parecía un triunfo seguro. La asamblea legislativa recomendó, por amplia mayoría, su destitución.

La reacción desproporcionada de ARENA revela la sorpresa causada por la derrota política. Los especialistas de la conspiración se lamentan de haber sido víctimas de una muy bien dirigida en su contra. Los que ante los señalamientos públicos se defienden exigiendo pruebas se quedaron sin palabra cuando les presentaron evidencia documental. Ironías de la vida nacional. Hasta ahora, la estratagema, que consistía en desafiar al que señala para que fundamente sus aseveraciones presentando pruebas, cuando debiera ser precisamente al revés, no había fallado. Arrinconados, se defienden alegando que la oposición está prejuiciada, lo cual es cierto, pero no más que ellos. Hay que reconocer, sin embargo, que, al concluir la interpelación, el presidente del Banco Central de Reserva ya contaba con la benevolencia de la mayor parte de la oposición, que se disponía a pronunciarse en contra de su destitución a cambio de una reforma radical de la legislación financiera.

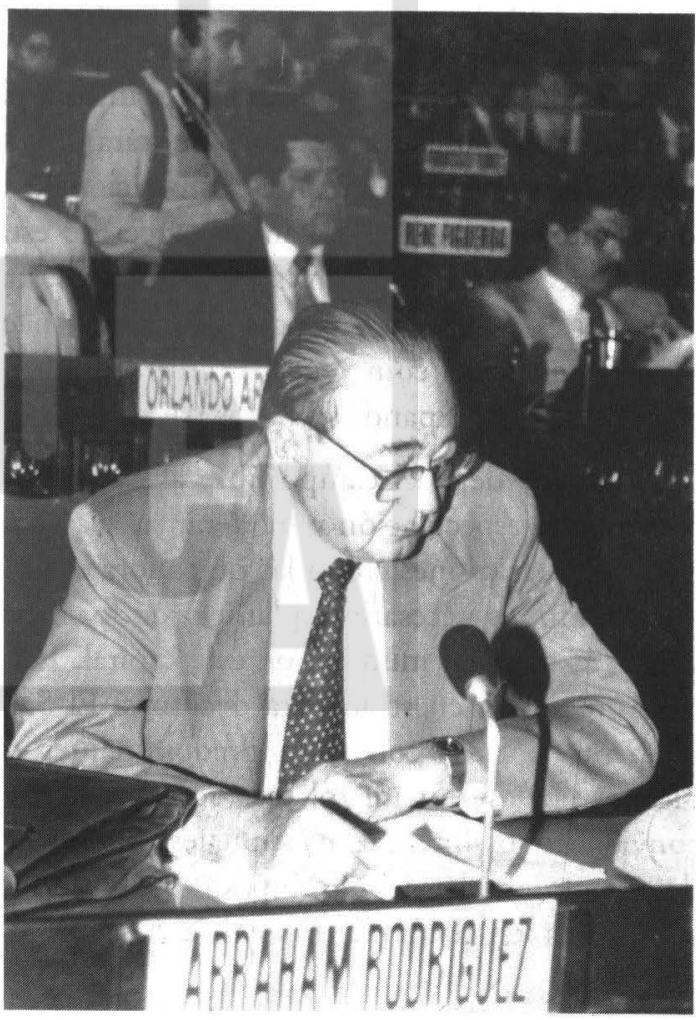


En todo este asunto que toca de lleno la realidad financiera del país, ARENA no ha sabido mirar por el bien público, sino que ha rendido a favorecer los intereses de un sector del gran capital. Mientras la hegemonía de este sector sobre el partido parece consolidarse, la posición de éste se complica de una manera no vista hasta ahora. La unidad que había caracterizado a las clases alta y media alta, donde ARENA tiene una clientela importante, experimenta fracturas graves, causadas por las fuerzas del mercado y las luchas por el poder. En lugar de buscar cómo restaurar la unidad fragmentada, ARENA se decanta por el sector más poderoso, abandonando al orro a su suerte o mejor dicho, a las fuerzas del mercado, que siempre favorecen a los más fuertes. ARENA no ha sabido o quizás no ha podido mantener una posición más ecuánime en lo que es un espinoso conflicto de intereses económicos y ambiciones políticas. Es así como el partido ha quedado en manos de uno de los grupos más poderosos del país, el cual, precisamente por su poder, no cuenta con la aceptación de aquellos que han sido excluidos.

En un segundo momento, quizás comprendiendo mejor las posibles consecuencias negativas de su primera actitud, contraria a una solución favorable a las personas estafadas, el gobierno ofreció una salida aceptable para intentar restituir la mayor parte del dinero perdido, esperando así acallar el bullicio de las protestas, aunque queda por ver el impacto que esto tendrá en el electorado.

Más allá del cálculo político, la coyuntura plantea otra cuestión que debe ser abordada con cierta urgencia. Se trata de dilucidar si la política cederá su lugar a los dictados del capital transnacional, dejando que éste decida sobre los asuntos nacionales. La importancia de esta cuestión para un gobierno empeñado en participar en la globalización estriba en que lo único realmente global es la especulación del capital transnacional en contraposición a las exportaciones y el comercio del tercer mundo, que encuentran toda clase de obstáculos para expandirse en los países industrializados.

Se puede dejar el campo libre al capital transnacional o intervenir para controlar la especulación y moderar su avaricia. Si se opta por lo primero, se repetirán situaciones como las que ahora el país lamenta; pero si se opta por lo segundo, es necesario replantear de forma drástica la función del Estado ante la expansión mundial de este capital. En cualquier caso, es obligatorio confrontar esta cuestión para decidir si El Salvador se dejará arrastrar simplemente por las corrientes predominantes del capitalismo mundial o si luchará por asumir un rol más activo, determinando qué tipo de inserción conviene a sus intereses naacionales. Prueba de ello es que, al final, el Estado salvadoreño ha debido responder, haciéndose cargo de su responsabilidad subsidiaria, en el caso de Finsepro e Insepro. 
Estos hechos demuestran que el gobierno actual no está preparado para enfrentar con éxito los desafíos planteados por la globalización. Predomina un optimismo ingenuo que piensa que la apertura al mercado internacional es, en sí misma, buena y, por lo tanto, de ella sólo pueden derivarse bondades para el país. Esta llamada de atención no está dirigida de forma exclusiva a ARENA, sino a todos los partidos políticos con posibilidad real para llegar al poder. La cuestión es inevitable, pero la respuesta no es simple.

\section{Un dramatismo perjudicial}

La vida nacional de por sí está cargada de un dramatismo intenso, tanto si se trata de asuntos constitucionales o financieros de gran transcendencia, como si se trata de fútbol. El drama vuelve interesante las coyunturas nacionales, pero no necesariamente contribuye a resolverlas de forma favorable para el país. Al contrario, con frecuencia se cae en extremos histriónicos y tragicómicos. Los medios de comunicación son los que más contribuyen a generar y alimentar este dramatismo innato en la idiosincracia nacional. La dramatización de personas, situaciones o temas se presta a la manipulación por parte de quien controla dichos medios. Sin embargo, es un arma peligrosa, eficaz para promover u ocultar; pero que, por su misma maleabilidad, puede volverse contra quienes la explotan.

Esta tendencia a la dramatización con su falta de objetividad y seriedad oscurece y vanaliza las coyunturas nacionales e incluso las internacionales. Las situaciones más serias se tornan intranscedentes por falta de análisis objetivos, sensibilidad humana y principios morales. La realidad nacional puede ser transformada en un partido de fútbol y viceversa, éste puede ser

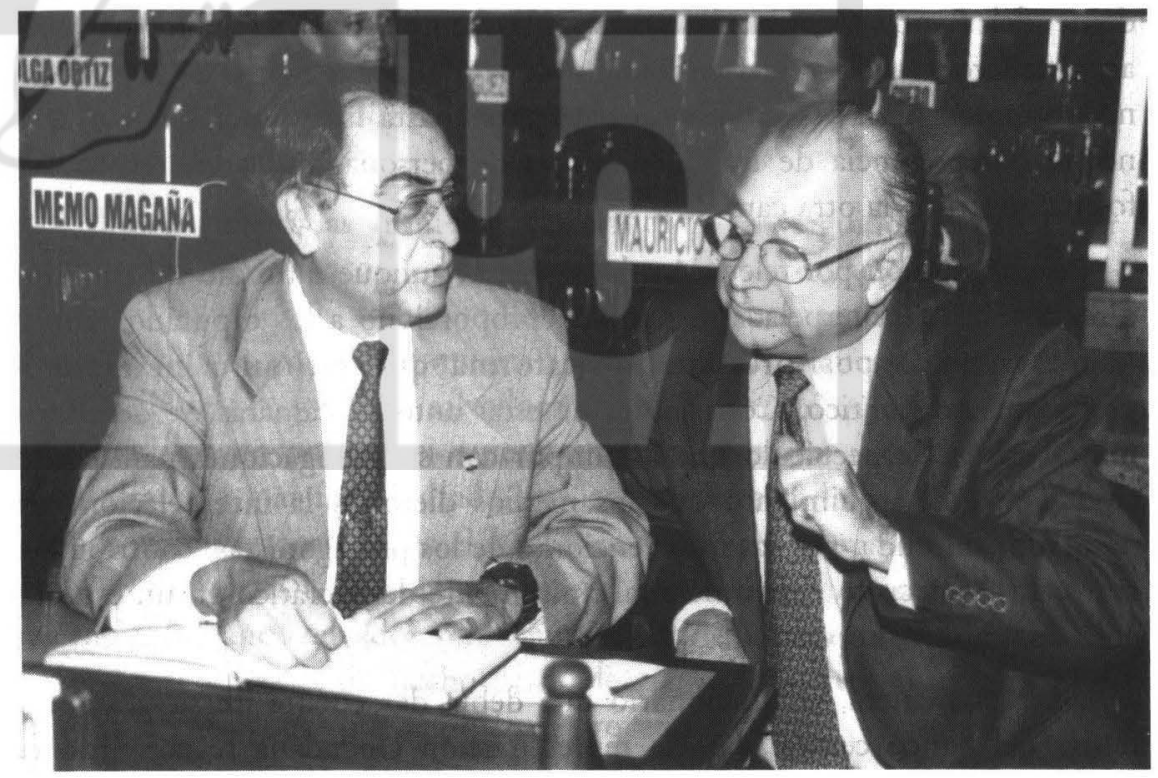


convertido en un asunto de máxima importancia para el país, opacando los acuciantes problemas del país. De esta manera, se generan confusiones, se introducen valores falsos y se fomentan actitudes superficiales, por lo general inmorales.

El dramatismo puede ser combatido tomando distancia de los acontecimientos, las personas o los temas, no dejándose envolver o llevar por las emociones fuertes que obnubilan el pensamiento y el juicio. Asimismo, una dosis de buen humor e incluso de irreverencia ayudaría muchísimo a disminuir las tensiones sociales y el impacto de una polarización política que, hasta cierto punto, por ahora parece ser inevitable, dada la configuración del espectro político.

ARENA alertó para prevenir que la interpelación se convirtiera en un espectáculo circense; pero, al final, explotando la proclividad al drama y utilizando con habilidad los recursos proporcionados por algunos medios de comunicación social influyentes, montó su propio espectáculo con éxito relativo. De esta manera, neutralizó a la oposición política, al punto que ésta se llegó a sentir interpelada, en lugar de ser ella la que interpelaba a un alto funcionario del poder ejecutivo. Este se dirigió a la asamblea legislativa desde el sitio reservado a su junta directiva durante todo el primer día, ocupando el lugar designado previamente en el primer plano al día siguiente, después de un acalorado debate. Además, asumió el papel de tecnócrata imperturbable -excepto cuando le insinuaron que había obtenido beneficios personales de la privatización de la banca- al extremo que exasperó a los diputados. El poder ejecutivo en pleno lo acompañó en lo que fue presentado como una ordalía política, olvidando que en los despachos ministeriales aguardaban asuntos nacionales de primera importancia - pero percibiendo correctamente que todo él estaba siendo interpelado en el presidente del Banco Central de Reserva. Los empleados del banco también acompañaron a su presidente de ocho de la mañana a cuatro de la tarde no obstante que las sesiones se prolongaron hasta las primeras horas de la noche. La presencia de un buen grupo de personas estafadas recordó de forma oportuna la otra cara de la realidad.

La transmisión por televisión de la sesión, aunque difundió información directa sobre la interpelación, también proporcionó a los diputados gubernamentales y opositores una plataforma que estimuló su afán de protagonismo político. Conscientes de estar ante las cámaras, se dedicaron más a crear el espectáculo que a cumplir con sus obligaciones para con la ciudadanía. El seguimiento que los medios dieron a la interpelación, alimentado, sin duda, por las intervenciones de los protagonistas, contribuyó a convertir un recurso constitucional típicamente democrático en un espectáculo de grandes proporciones.

De esta manera, el funcionario que debía dar cuenta de su gestión al frente del banco central ante la representación ciudadana se convirtió en 


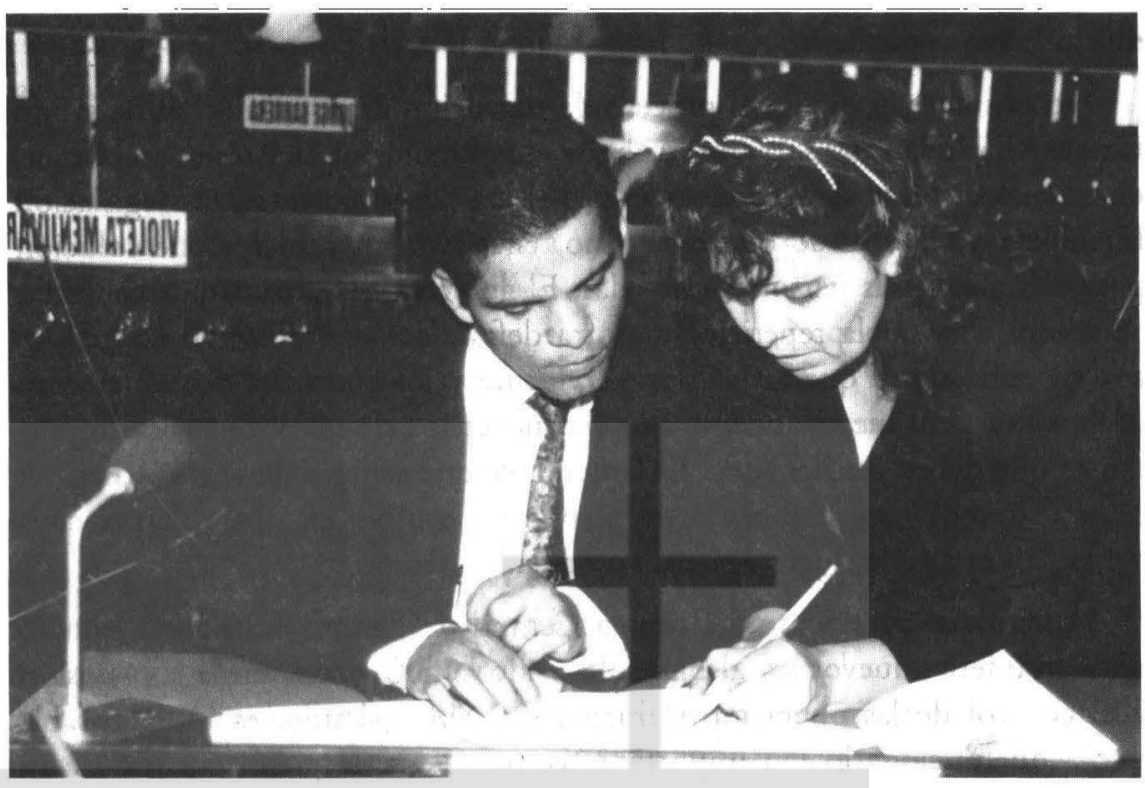

víctıma; la legıslacion bancarıa que repıtıo incansadie en sus respuestas se transformó en una intervención muy técnica, fuera del alcance de los no iniciados; lo que la Constitución garantiza como un recurso para equilibrar los poderes - que pudo evitarse si el poder ejecutivo hubiera reaccionado de forma diligente y apropiada - se transformó en una amenaza para la estabilidad financiera del país. Es cierto que, al final, la oposición política se sintió frustrada y engañada - en parte por sus propias limiraciones-, pero la actuación del presidente del Banco Central de Reserva y con él, la del poder ejecutivo, no fue aplaudida más que por los círculos gubernamentales y financieros y los sectores favorecidos de ARENA. Es cierto que las responsabilidades no pudieron ser establecidas, pero existe la certeza que el poder ejecutivo no ha dicho todo lo que sabe $y$, sobre lo poco que ha dicho, no ha hablado con verdad.

El drama superó las fronteras nacionales y fue seguido de cerca por aquellos gobiernos, bancos, empresas, instituciones y organizaciones interesadas en El Salvador. El fraude millonario y sus consecuencias no han pasado desapercibidos para la comunidad internacional, poniendo una presión adicional sobre un gobierno salvadoreño consciente de que tiene que proyectar una imagen positiva si quiere atraer la inversión extranjera. Menos dada al drama y más familiarizada con las estafas, para la comunidad internacional lo importante no es el hecho mismo, sino la respuesta gubernamental y empresarial, lo cual no parece haber sido comprendido por el gobierno y la banca salvadoreñas, a juzgar por la lentitud con la cual reaccionan. La apertura es un hecho de doble vía, no sólo trae el mundo exterior a El Salvador, sino que también lo proyecta en él. 


\section{Un balance positivo}

No obstante lo dicho, el proceso de transición democrática habría salido fortalecido de la interpelación. Aunque el gobierno intentó restar importancia al escándalo, acabó reconociendo que era necesario revisar la legislación financiera $y$, más tarde que temprano, encontró un principio de solución para algunas de las personas estafadas. El gobierno y la banca parecen estar decididos a evitar la repetición de otra defraudación similar. Al comienzo, ambos enfatizaron que la legislación vigente y los controles existentes eran adecuados; pero luego tuvieron que reconocer la existencia de vacíos importantes que deben ser llenados. Es lamentable que se haya tenido que llegar a estos extremos para comprometer al poder ejecurivo en una reforma cuya necesidad es a todas luces evidente desde hace tiempo.

Destituir al presidente del Banco Central de Reserva no habría evitado necesariamente nuevos fraudes ni subsanado la negligencia en la supervisión y el control de las operaciones financieras. Sin embargo, es indispensable que a un funcionario tan importante como éste se le pidan cuentas de su gestión y que éste, por su lado, asuma sus responsabilidades técnicas y políticas. El que haya actuado bien en el área monetaria no lo exime de otras responsabilidades también importantes. El presidente de la república también está obligado moralmente a dar una explicación al país sobre su participación en este oscuro asunto.

El fraude millonario y sus consecuencias no han pasado desapercibidos para la comunidad internacional,

poniendo una presión adicional sobre un gobierno salvadoreño

consciente de que tiene que proyectar una imagen positiva si quiere atraer la inversión extranjera.

Ahora bien, además de establecer las responsabilidades de los funcionarios, hay que revisar con cuidado la legislación relacionada con las actividades bancarias y financieras, llenando vacíos y extremando controles. La eficacia de esta puesta al día de la legislación depende del fortalecimiento institucional, encargado de vigilar dichas operaciones. Todos, tanto los empresarios objeto de esta supervisión como los funcionarios encargados de ella, deben ser plenamente conscientes que son responsables de sus actos, de los cuales deben dar cuenta ante la ley y la sociedad. El pais necesita ambas cosas, que los funcionarios, sobre todo lns altos, sepan dar cuenta de sus actuaciones y que la sociedad y el Estado ejerzan su derecho a pedirlas, y una nueva legislación de las finanzas, más en concordancia con su expansión 
especulativa. A la interpelación se debe que ahora haya más conciencia sobre ambas necesidades.

Cada vez es más difícil mentir y en la medida en que la sociedad esté mejor informada y más alerta será más difícil aún. Los recursos utilizados en el pasado para ocultar la verdad, ya no producen el resultado deseado. El poder ejecutivo debe saberse vigilado no sólo por la sociedad, los políticos y los medios de comunicación social, sino también por aquellos que siguen de cerca el desarrollo del proceso salvadoreño en el exterior. Esta doble vigilancia, interna y externa, ejerce una presión sana para ajustar cada vez más el discurso a los hechos.

El Estado tiene que aprender a asumir sus responsabilidades. Ya no se puede sostener, tal como lo hizo el presidente Calderón, quizás sin pensar mucho en lo que afirmaba, que los fraudes financieros son problemas "de índole moral y actuaciones humanas que están fuera del control de las instituciones y leyes". Según esto, cualquiera puede atentar contra el sistema financiero, pues no habría ley ni institución ni instancia superior que supervisase, pidiese cuenta y sancionase. Toda acción humana tiene un componente moral, que pertenece al ámbito de lo individual; pero también tiene otro de carácter social, que se encuentra sometido al ámbito de la ley y las instituciones y, por consiguiente, es competencia del Estado.

El sistema financiero ya no puede seguir abandonado al arbitrio de un reducido grupo de banqueros, antiguos compañeros de colegio y viejos amigos, que deciden entre ellos lo mejor para sí mismos y sus empresas. Mucho menos se debiera permitir que utilicen el poder del Estado para perseguir sus fines particulares. Mientras no se rompa la exclusividad de este cerrado

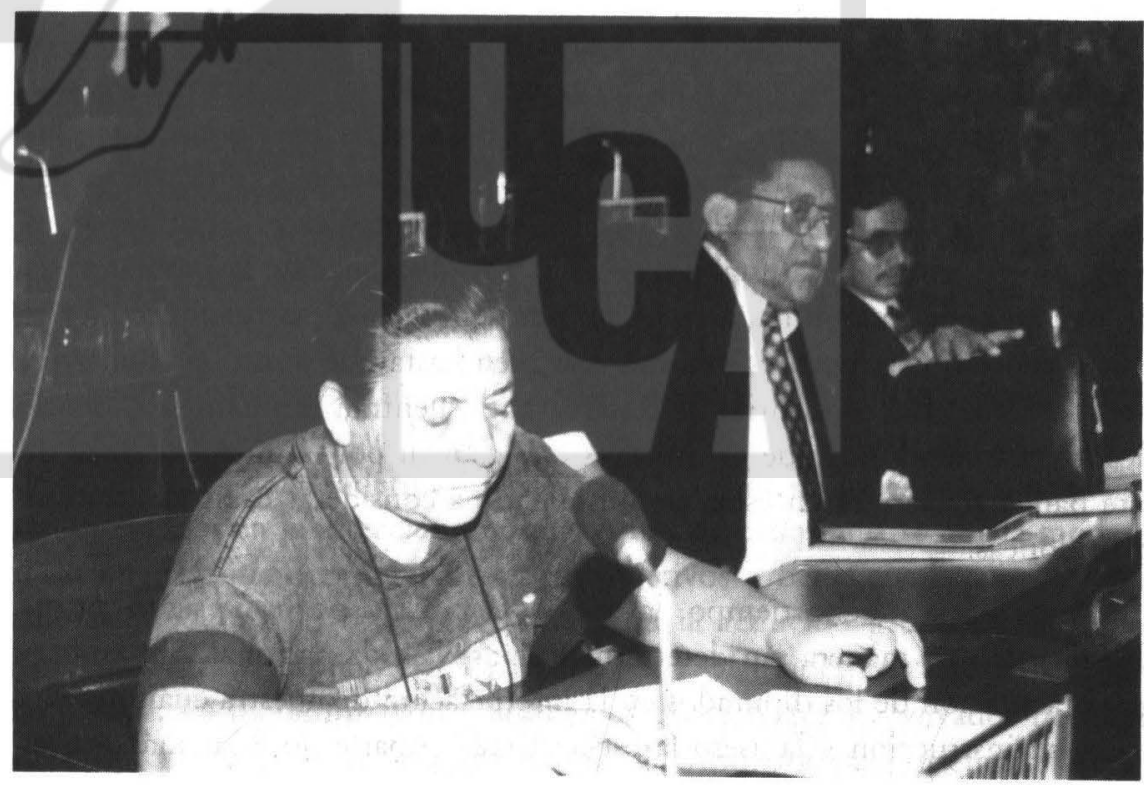


círculo, los ideales modernizadores del neoliberalismo serán inalcanzables. En este sentido, la independencia del banco central, de las superintendencias y del gobierno mismo del sector bancario y financiero es una necesidad urgente para el bienestar de la sociedad.

A primera vista, el gobierno y el sector financiero parecen estar de acuerdo con este objetivo general, el cual se puede encontrar en todos los discursos, a veces incluso expresado en un lenguaje desconcertante por su compromiso con el cambio social. Pero miradas las cosas con más detenimiento, todavía se observan grandes obstáculos que vencer, en particular, mentalidades que transformar. Los banqueros han demostrado no tener disposición para comprender los problemas nacionales. Para ellos, el presidente del Banco Central de Reserva es idóneo para el cargo porque ha conseguido y mantenido la estabilidad monetaria. Desde una perspectiva estrictamente formal, así es; pero en la práctica, el presidente del Banco Central de Reserva está más implicado de lo que parece en las otras áreas del quehacer económico. Por eso mismo y porque el estado de la pobreza y la estabilidad macroeconómica secodeterminan, el bienestar de la población debiera ser considerado como una de sus responsabilidades prioritarias.

además de establecer las responsabilidades de los funcionarios, hay que revisar con cuidado la legislación relacionada con las actividades bancarias y financieras, llenando vacíos y extremando controles.

En su afán por defender al presidente del Banco Central de Reserva de los ataques de la oposición política y para no sentar un precedente que ponga a merced de ésta la permanencia de los altos funcionarios en sus cargos, la banca nacional argumentó que su destitución significaría el derrumbe del sistema financiero, lo cual es inaceptable. $\mathrm{El}$ argumento es especioso, puesto que la estabilidad no puede depender de la permanencia de una persona determinada en la presidencia de una institución como el banco central. Esta postura muestra más bien hasta qué punto la banca y el presidente del Banco Central de Reserva se encuentran mutuamente identificados. Es paradójico que los mismos que claman por la independencia de este banco se cierren, en estas circunstaneias, a considerar otras alternativas más idóneas.

Desde hacía mucho tiempo, la oposición política no hacía sentir su influencia de una manera tan determinante para la vida nacional. Sin embargo, la actuación de los diputados en la interpelación demuestra cuán necesaria es su instrucción y la asesoría especializada. Aparte de sacar más prove- 
cho de la interpelación misma, la democratización hubiera salido más fortalecida si hubiesen sido más diligentes. Invocando el consenso, aceptaron unas reglas que los pusieron en ridículo, al permitir que el interpelado evadiera aquellas cuestiones que podían comprometerlo. El consenso no consiste en la sumatoria de posturas - mucho menos cuando éstas carecen de fundamento sólido. Así, el cuestionario incluyó toda clase de preguntas, sin priorizar y sin garra. La oposición tenía los votos suficientes para imponer un buen cuestionario así como los tuvo para solicitar la destitución. El consenso no es un fin, sino un medio. La inexperiencia en el quehacer legislativo y la ignorancia de los asuntos financieros de la mayoría de los diputados pusieron en peligro un recurso constitucional muy necesario para controlar al poder ejecutivo desde la oposición. A todo esto habría que agregar las intenciones mezquinas de algunos diputados, más preocupados por obtener ventajas particulares que por impulsar los intereses comunes. Al no descubrir la verdad, la interpelación corre peligro de perder relevancia.

El sistema financiero ya no puede seguir abandonado al arbitrio de un reducido grupo de banqueros, antiguos compañeros de colegio y viejos amigos, que deciden entre ellos lo mejor para sí mismos y sus empresas.

Ahora bien, esta relevancia, tal como está planteada, es cuestionable. Su alcance es muy limitado para lo que debiera ser. En consecuencia, la interpelación como mecanismo al servicio de la democratización también debiera ser sometida a un proceso de revisión profunda. En los parlamentos y congresos de otros países se pueden encontrar modelos, que, si son bien utilizados, podrían contribuir mucho a que la democracia fuese cada vez más real. Es normal que quien detenta el poder ejecutivo recele de esta clase de propuestas y se oponga a ellas; sin embargo, de lo que se trata no es de proteger un determinado gobierno del cuestionamiento de la opinión pública, sino de promover la democratización del país.

El capitalismo no es sinónimo de democracia ni ésta lleva forzosamente al progreso y al bienestar. No se trata, por tanto, de cambiar por cambiar o de modernizar por modernizar, porque las transformaciones no siempre están orientadas en la dirección deseada. Antes de pronunciarse por la modernización hay que preguntarse por sus objetivos y beneficiarios directos. Si sólo se moderniza para favorecer más aún al reducido grupo privilegiado que concentra el capital, el saber y el poder, tal modernización debiera ser rechazada. La modernización y la democratización que El Salvador necesita deben proponer una intervención estatal determinante para orientar el desa- 
rrollo económico, regulando el funcionamiento del mercado; prestar atención a la dimensión institucional del desarrollo sostenible; promover una política industrial y agropecuaria de largo plazo; conducir el país con una visión regional; comprometer al sector privado con el desarrollo sostenible del país; promover niveles elevados de integración y movilidad social; distribuir el ingreso de forma más equitativa; crear una estructura social igualitaria y promover una identidad nacional integradora.

El gran ausente en esta coyuntura es la moral, como si ésta no fuera importante para configurar la sociedad positiva y humanamente. Todos los actores se esforzaron por desconocer sus obligaciones morales para con la sociedad, el Estado y sus principios de conducta personal. En lugar de avanzar en transparencia se acentuaron las oscuridades en cuanto al sistema financiero, la interpelación y la forma de gobernar. Si mentir es cada vez más difícil, la tolerancia y a veces, incluso, la complacencia con la inmoralidad pública son todavía lacras que deben ser superadas. En una sociedad con una mayor conciencia civil y sentido de lo moral ningún alto funcionario hubiera podido mantenerse en su cargo ante acusaciones como las que se lanzaron contra el presidente del banco central salvadoreño. Incluso, el mismo presidente de la república se habría visto en apuros. La interpelación pone en evidencia la debilidad de la sociedad salvadoreña, pero también su falta de sentido de lo moral.

Las presiones que provienen de fuera más las necesidades internas obligan a empujar con más fuerza el proceso iniciado a raíz de la finalización del conflicto armado. Es necesario aprovechar al máximo esta necesidad de cambiar para convertirla en virtud, cambiando en favor del bienestar de las mayorías salvadoreñas.

San Salvador, 20 de sepriembre de 1997. 